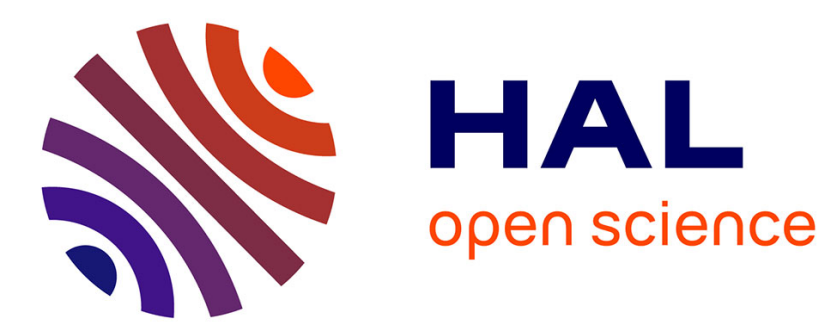

\title{
Prediction of elastic anisotropic thermo-dependent properties of discontinuous fiber-reinforced composites
}

\author{
D Lopez, Sandrine Thuillier, Y. Grohens
}

\section{To cite this version:}

D Lopez, Sandrine Thuillier, Y. Grohens. Prediction of elastic anisotropic thermo-dependent properties of discontinuous fiber-reinforced composites. Journal of Composite Materials, In press, 10.1177/0021998319889397 . hal-02478136

\section{HAL Id: hal-02478136 \\ https://hal.science/hal-02478136}

Submitted on 13 Feb 2020

HAL is a multi-disciplinary open access archive for the deposit and dissemination of scientific research documents, whether they are published or not. The documents may come from teaching and research institutions in France or abroad, or from public or private research centers.
L'archive ouverte pluridisciplinaire HAL, est destinée au dépôt et à la diffusion de documents scientifiques de niveau recherche, publiés ou non, émanant des établissements d'enseignement et de recherche français ou étrangers, des laboratoires publics ou privés. 


\title{
Prediction of elastic anisotropic thermo-dependent properties of discontinuous fiber reinforced composites
}

\author{
D. Lopez ${ }^{\mathrm{a}, \mathrm{b}}$, S. Thuillier ${ }^{\mathrm{a}}$, Y. Grohens ${ }^{\mathrm{a}}$ \\ a Univ. Bretagne Sud, IRDL, UMR CNRS 6027, F-56100 Lorient, France \\ ${ }^{\text {b}}$ RENAULT Technocentre, 1 Avenue du Golf, 78280 Guyancourt, France
}

\begin{abstract}
.
This study is focused on the micromechanical prediction of temperature-dependent elastic properties of a composite made of a polypropylene matrix reinforced with discontinuous glass fibers. Firstly, an experimental investigation of the mechanical behavior is presented. Specimen are cut from injection-molded rectangular plates using a pattern based on fiber orientation. The microstructure is investigated by X-ray tomography at the specimen center and an average orientation tensor is calculated. Tensile tests are performed over a temperature range from ambient temperature to $85^{\circ} \mathrm{C}$ and dispersion of mechanical properties is rather low; moreover, they are representative of the ones measured out of an industrial injected part. Then, the evolution of elastic properties with orientation and temperature is analyzed and compared with numerical predictions calculated with Mori-Tanaka homogenization scheme.
\end{abstract}

Key words: Discontinuous fiber composite, Thermoplastic matrix, Elastic properties, Temperature effect, Micromechanical prediction

\section{Introduction}

Thermoplastic polymers reinforced with discontinuous fibers have been widely used for several years to reduce weight and develop new designs at competitive prices. They are used in the automotive industry with usual fiber content in the range between $30 \mathrm{wt} \%$ and $50 \mathrm{wt} \%$, e.g. a roof bar (1), a clutch pedal (2), a fuel rail (3), an instrument panel (4), a front-end module (5). Polypropylene (PP) is commonly used with glass fibers because the composite exhibits interesting mechanical properties for a high performance over price ratio, low processing temperatures with a glass transition temperature $T_{\mathrm{g}}$ below ambient temperature $(6,7)$ and also low water absorption (8). Such automotive components must resist demanding service life conditions, e.g. elevated temperatures (a few tens of degrees) during a few hours and meet thermo-mechanical specifications. Virtual design is then a necessity to optimize the proper use of these composites, while avoiding overestimating the part thickness. The reliability of this virtual design, based on finite element simulations, depends on the modeling of the anisotropic thermo-mechanical behavior of these materials.

The mechanical properties depend not only on fiber length or aspect ratio, shape and thickness of mold cavity but also on orientation and dispersion of the fibers. Indeed, injection-molded composites reinforced with discontinuous fibers display a very complex spatial fiber distribution (9-12) and the anisotropy related to the fiber orientation must be considered (13-15). Mechanical characterization is often performed in tension. However, as the microstructure is heterogeneous and anisotropic, the orientation of the tensile direction is defined with respect to the injection 
direction but also to the fiber orientation (or microstructure). A first way is to inject samples directly in their final shape $(16-18)$ but only one fiber orientation and one tensile direction can be investigated. The second and main trend is to consider only the central area of a rectangular plate: samples are rotated around this point and tensile tests are carried out at different directions for a fixed microstructure $(1,10,19,20)$. However, only one sample is cut out of one plate. Several specimen can be cut with the same orientation in a plate, thus neglecting the planar fiber orientation distribution over the plate (21). However, in accordance to numerical predictions (10), X-ray computed microtomography reveals that distribution of fiber orientation depends on the specimen location (22). Though only a few studies consider this distribution, it has a sensitive effect on elastic properties (23). These results highlight the importance of not neglecting fiber orientation distribution over the specimen as a source of variability of the mechanical properties. Indeed, a very large dispersion in terms of stress at rupture in tension, from $40 \mathrm{MPa}$ to $57 \mathrm{MPa}$, is recorded for the same load direction but for several sample locations, corresponding to an average orientation tensor component from 0.44 to 0.55 (22) for a PP reinforced with glass fibers. The idea is then to represent the microstructure by using local orientation tensors (1).

Structural parts may support in service demanding thermo-mechanical conditions and the material behavior must be tested under similar conditions. Temperature effect on mechanical behavior is not commonly observed in literature for polymer matrix composites $(15,19,24)$, however its influence must be considered for a variety of applications, e.g. fatigue (25). Temperature ensures a predominant role in the material behavior mainly due to the viscosity of the matrix (26), e.g. Young's modulus of PP decreases by $75 \%$ at $90^{\circ} \mathrm{C}$ compared to its value at ambient temperature (27). The same decrease is recorded for composites, e.g. glass fiber reinforced polyamide 6-6 (24) and PP reinforced by quasiunidirectional glass. In automotive applications, the typical temperature range is between $-40^{\circ} \mathrm{C}$ and $130^{\circ} \mathrm{C}$.

The temperature-dependent elastic behavior of an injection molded PP reinforced with discontinuous glass fibers is addressed in the present paper. Material description and experimental procedure, including sample preparation and cutting, X-ray computed micro-tomography and tensile test, are detailed in section 2 . Section 3 is dedicated to experimental results on local fiber orientation, characterized by an average orientation tensor, and tensile test results under isothermal loading conditions. Finally, section 4 focuses on a micromechanical prediction of elastic properties regarding anisotropy and temperature effect, using Mori-Tanaka model.

\section{Material and experimental procedure}

\subsection{Material}

In this study, a glass fiber reinforced PP named PPGFL40 is considered, with a fiber content of $40 \mathrm{wt} \%$. Rectangular plates of dimensions $179 \mathrm{~mm} \times 240 \mathrm{~mm}$, with a constant thickness of $2.75 \mathrm{~mm}$, are injected in industrial conditions at Technocentre Renault. The injection speed is $30 \mathrm{~mm} \cdot \mathrm{s}^{-1}$ and the mold temperature $250^{\circ} \mathrm{C}$.

A calcination method is chosen to verify the fiber content. Five samples of $2.75 \times 10 \times 20 \mathrm{~mm}^{3}$ dimensions are cut from three different plates and heated up to $750^{\circ} \mathrm{C}$ during $30 \mathrm{~min}$ according to the standard NF EN ISO 1172 . The average dispersion of fiber content between plates is less than $2.8 \%$ whereas samples from the same plate exhibit a maximum relative gap of $3.5 \%$. The maximum relative gap reaches an acceptable $5 \%$ regarding the $40 \%$ aimed at 
during elaboration of the material. This weak dispersion of the fiber content shows a good control of the injection process. The initial fiber length is $11 \mathrm{~mm}$ with a diameter of $17 \mu \mathrm{m}$. These values are common ones for such a composite, e.g. $(28,29)$. To determine the fiber length after injection, specimens are incinerated and then dispersed in a dilute solvent to separate the fibers. The fiber length is measured with an optical microscope on ten specimens showing almost a hundred fibers each and extracted from several areas. The resulting fiber length average is $1.5 \mathrm{~mm}$ and the median value is around $0.8 \mathrm{~mm}$. The smallest value is around $0.3 \mathrm{~mm}$ when a maximum of $11 \mathrm{~mm}$ is sometimes reached, and therefore the composite should be qualified as semi-long fiber material $(28,30)$.

Three temperatures representative of common industrial specifications are considered in this study: $23^{\circ} \mathrm{C}, 60^{\circ} \mathrm{C}$ and $85^{\circ} \mathrm{C}$. Only positive temperatures are chosen, to represent desert-like conditions responsible for creep. Main properties of each constituent of PPGFL40 are specified in Table 1. Fiber elastic properties are considered unchanged in this range of temperature.

\begin{tabular}{|c|c|c|c|c|c|c|c|}
\hline \multicolumn{3}{|c|}{ Glass fibers } & \multicolumn{5}{|c|}{ PP matrix } \\
\hline \multirow{2}{*}{$E_{f}[\mathrm{MPa}]$} & \multirow{2}{*}{$v_{f}$} & \multirow{2}{*}{$\rho_{\mathrm{f}}\left[\mathrm{g} \cdot \mathrm{cm}^{3}\right]$} & \multicolumn{3}{|c|}{$E_{m}[\mathrm{MPa}]$} & \multirow{2}{*}{$v_{m}$} & \multirow{2}{*}{$\rho_{m}\left[\mathrm{~g} \cdot \mathrm{cm}^{3}\right]$} \\
\hline & & & $23^{\circ} \mathrm{C}$ & $60^{\circ} \mathrm{C}$ & $85^{\circ} \mathrm{C}$ & & \\
\hline 72000 & 0.23 & 2.6 & 1720 & 792 & 587 & 0.24 & 0.946 \\
\hline
\end{tabular}

Table 1. Fiber and matrix properties at several temperatures (Renault data). Young's modulus, Poisson's ratio and density $E_{i}, v_{i}, \rho_{i}$ subscript $i=f$ or $m$ for fiber or matrix respectively.

Dynamic Mechanical Analysis (DMA) tests are carried out with a viscoanalyser ARES G2 - TA Instruments at Technocentre Renault. Samples dimensions are $56 \times 10 \times 2.75 \mathrm{~mm}^{3}$. They are cut from injected plates in several areas at $0^{\circ}$ and $90^{\circ}$ regarding the injection direction. Analysis is performed at $1 \mathrm{~Hz}$ in torsion mode and the temperature run from $-30^{\circ} \mathrm{C}$ to $150^{\circ} \mathrm{C}$ at a heating rate of $2^{\circ} \mathrm{C} / \mathrm{min}$ under a controlled sinusoidal strain of $0.15 \%$. Evolution of the storage modulus $G^{\prime}$ and loss factor tan $\delta$ versus temperature is shown in Fig. 1 for unfilled PP and PPGFL40, for two samples. As the temperature rises, the storage modulus decreases continuously when the loss factor increases and two peaks can clearly be seen. The first one corresponds to the glass transition and occurs around $0^{\circ} \mathrm{C}$. The second one, at around $90^{\circ} \mathrm{C}$, corresponds to the beginning of melting. Incorporation of fibers reduces $\tan \delta$ peak height by restricting the movement of macromolecules (31). Temperatures which are considered in this study are situated in a same relaxation state from $23^{\circ} \mathrm{C}$ to $85^{\circ} \mathrm{C}$. Though the dispersion is higher for the composite, the reproducibility for both matrix and composite is satisfying. 


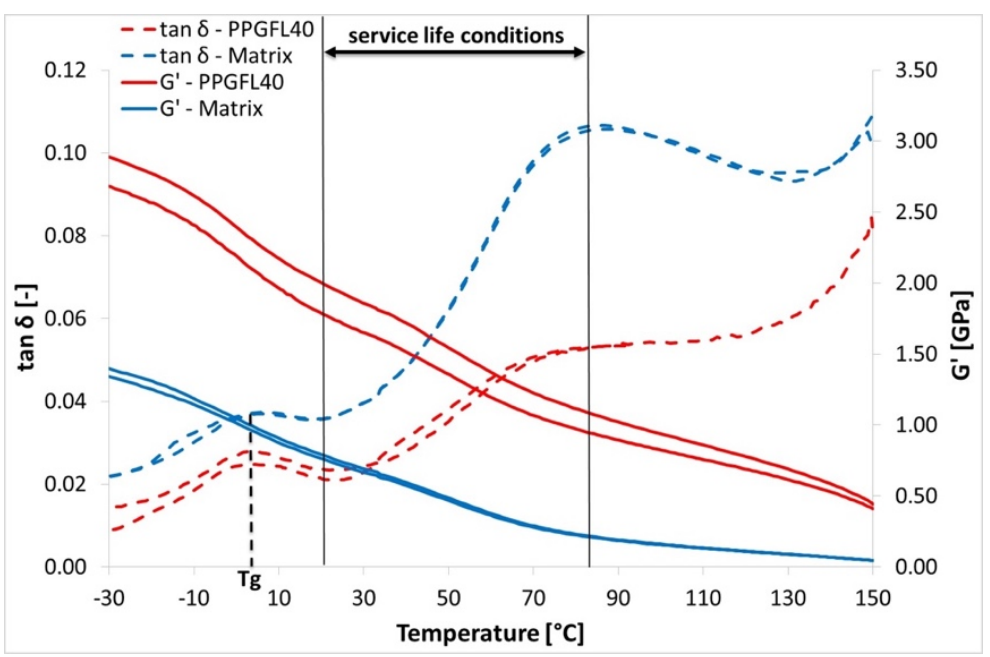

Fig. 1. $\mathrm{G}^{\prime}$ and $\tan \delta$ obtained with DMA at $1 \mathrm{~Hz}$ between $-30^{\circ} \mathrm{C}$ and $150^{\circ} \mathrm{C}$ for PP and PPGFL40.

\subsection{Cutting pattern of tensile specimen}

To cover the whole plate in an easy way, orientation intensity is observed by terahertz 2D imaging based on reflection and transmission of high frequency waves, located between infrareds and microwaves in the electromagnetic spectrum (32). Result is shown in Fig. 2(a); a value of 1 (red areas) represents a strong fiber orientation in a direction which is not known. Two methods are considered for the tension, i.e. aligning the tensile direction with the injection direction, at several locations in the plate and rotating the tensile direction. The cutting pattern is defined based on the results of Fig. 2(a) and is shown in Fig. 2(b). Only three main angles relatively to the injection direction are considered to limit the number of mechanical tests: $0^{\circ}, 45^{\circ}$ and $90^{\circ}$. It is possible to cut out seven samples in the same plate corresponding to five configurations, three in the longitudinal direction (named L1, L2 and L3) considering the plate symmetry (22) and two in the transverse one (called T1 and T2). Two more configurations are taken in a different plate at $45^{\circ}$ (45-1 and 45-2). This cutting pattern has the benefit to cover a large range of fiber orientations and to avoid a waste of materials. Specimen cutting is done by low speed machining and a cooling system and proper knife edge angle to avoid affecting material properties. Samples have a dog-bone shape with a gauge area of $50 \times 10$ $\mathrm{mm}^{2}$ and dimensions according to the standard NF EN ISO-527-b $(14,24)$. They are stored several days in a controlled atmosphere room, with temperature and hygrometry rate regulated respectively at $23^{\circ} \mathrm{C}$ and $50 \%$. Tensile tests are carried out at three temperatures under isothermal conditions, i.e. $23^{\circ} \mathrm{C}, 60^{\circ} \mathrm{C}$ and $85^{\circ} \mathrm{C}$, representative of potential service life conditions. It should be emphasized that ambient temperature is not strictly imposed at $23^{\circ} \mathrm{C}$, whereas it is regulated at higher values. Mechanical tests are carried out on an Instron electro-mechanical testing machine with a load cell of maximum capacity $10 \mathrm{kN}$. The distance between the fixed grip and the moving one is initially set at $108 \mathrm{~mm}$. The local displacement is measured with an extensometer of $25 \mathrm{~mm}$ gauge length set in the middle of the sample. Tests are performed at several crosshead speed, corresponding to almost constant strain rates of $10^{-5}, 10^{-4}$ and $10^{-3} \mathrm{~s}^{-1}$. For each configuration, 3 to 5 tests are conducted at room temperature, to check the reproducibility. And, as it is very good, at least two samples are tested at higher temperatures. After pre-conditioning at the test temperature, the isothermal test is started. At least $30 \mathrm{~min}$ are required to reach the temperature of the test with the 
maximum rate of $5^{\circ} \mathrm{C} / \mathrm{min}$. To control the temperature, thermocouples are located on the sample and on the grips. Cauchy stress and logarithmic strain are calculated from raw data and used to plot the graphs.

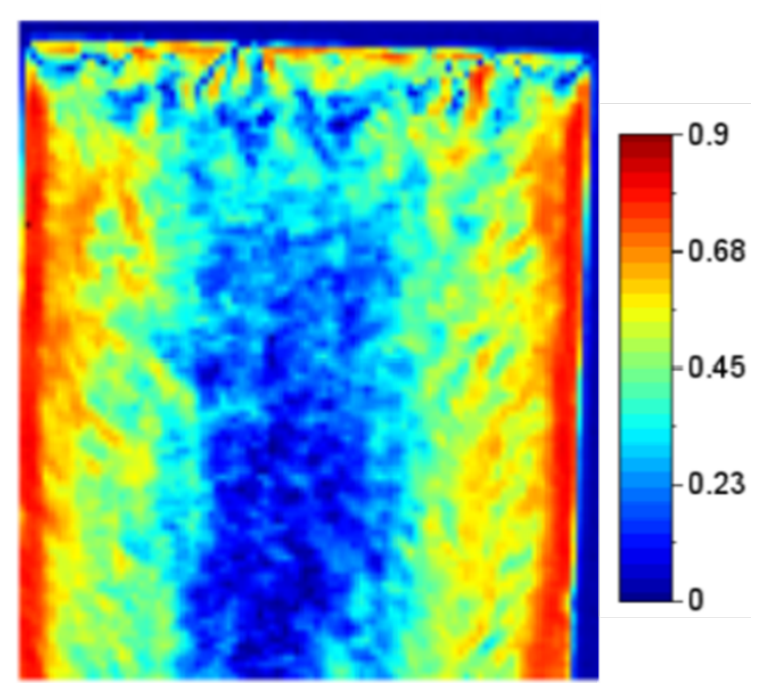

(a)

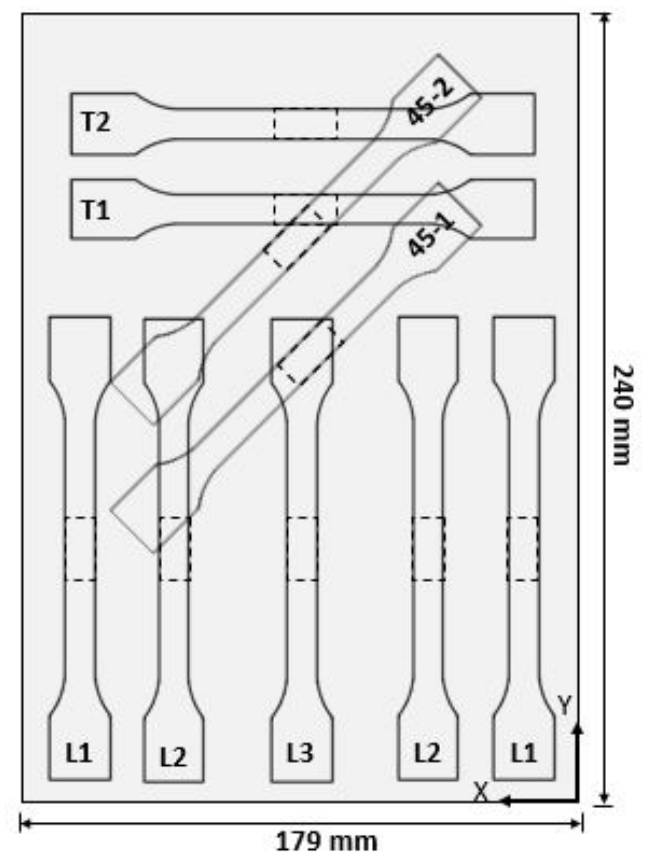

(b)

Fig. 2. Fiber orientation intensity obtained by terahertz analysis on PPGFL 40 plate (a) and cutting pattern for $0^{\circ}$, $90^{\circ}$ and $45^{\circ}$ samples, regarding the direction of injection, highlighted by the black arrows. Dotted lines correspond to areas observed by X-ray micro-tomography (b). The injection gate is located at the top of the plate.

\subsection{X-ray micro-tomography}

The local microstructure is also experimentally investigated by means of X-ray micro-tomography, which is the most common non-destructive method used to observe fiber orientation $(33,34)$. Only central areas of the tensile specimen are considered with sample dimensions of $10 \times 20 \times 2.75 \mathrm{~mm}^{3}$ and cut out of two injected plates. Water jet cutting is used to avoid pulling out of fibers. Several 2D scans are taken with specific values given in Table 2 and 3D images are then built with a dedicated algorithm; image analysis is carried out by (35).

\begin{tabular}{|c|c|c|c|c|c|}
\hline X-ray source & Energy & Projections number & Break time & Voxel size & Analyzed volume \\
\hline ESRF, BM05 & $90 \mathrm{keV}$ & 4500 & $0.12 \mathrm{~s}$ & $2.25 \times 2.25 \times 2.25 \mu \mathrm{m}^{3}$ & $3.0 \times 8.8 \times 19.3 \mathrm{~mm}^{3}$ \\
\hline
\end{tabular}

Table 2 . X-ray micro-tomography parameters.

To derive quantitative data, the average orientation tensor $\mathbf{A}(36)$ in the thickness of each specimen is calculated from X-ray micro-tomography analysis. The fibers appear in white and the matrix in grey in the reconstructed images and the voxel size is given in Table 2. The orientation vectors $\boldsymbol{p}^{i}$ of the fibers are calculated with a method based on grey nuance gradient around fiber neighboring and using a dedicated tool developed by Novitom. Then, the second order orientation tensor is calculated based on orientation vectors $\boldsymbol{p}^{i}$ for all voxels $N$ of the fiber phase in the chosen frame, with equation 1 . Only the components $A_{x x}$ and $A_{y y}$ (the frame is defined in Fig. $2 b$ ) are given here because they correspond to the highest values. 


$$
\boldsymbol{A}=\frac{1}{N} \sum_{i=0}^{N} \boldsymbol{p}^{i} \otimes \boldsymbol{p}^{i}
$$

\section{Results}

Monotonic uniaxial tensile tests are performed at ambient and elevated temperatures for several fiber orientations, to highlight the fiber orientation effect and to check the reproducibility between two different plates. Moreover, the local fiber orientation is characterized by the components of the orientation tensor, averaged over the sample thickness.

\subsection{Fiber orientation}

Fig. 3 shows the heterogeneity of the microstructure, characterized by a skin-core structure (28). The fiber orientation is mainly composed of two skin layers with preferential orientation parallel to the flow direction, and a core region with orientation perpendicular to the flow and in the plane of the part, which is classical for injected parts. Such a distribution is sometimes neglected, especially in industrial cases, to simplify the mechanical investigation and material behavior representation. As a consequence, an average orientation tensor (36) over the thickness is introduced in constitutive equations and this approach gives a reliable prediction of the elastic properties $(20,37,38)$. A similar approach is then considered in this study. Fig. 3(b) shows fibers mainly oriented in the injection direction corresponding to the L1 configuration contrary to Fig. 3(c) which displays a random orientation for the L3 one. This planar distribution of the fiber orientation is also highlighted in (4) for an industrial part in PP reinforced by 20 wt\% of glass fibers. Experimental evaluation of the orientation tensor components is given in Table 3 for five configurations showing a stark contrast. Whatever the orientation, $A_{z z}$ is very small, of the order of 0.037 . Moreover, all the nondiagonal components are very close to zero. Except for L1, which is a rather oriented configuration, all the other components are very close to 0.5 . In addition, $L 1$ is the only one to show a relative gap between $A_{x x}$ and $A_{y y}$ superior to $50 \%$. On the contrary, L3 and T1 exhibit a higher $A_{x x}$ value than $A_{y y}$. It can be seen that $A_{y y}$ values for L1 and L3 are very different, with a relative gap around 39\%, though they both correspond to tension in the injection direction. However, for a PP reinforced by $30 \mathrm{wt} \%$ of glass fibers and similar plate thickness (22) obtain close values, respectively around 0.7 and 0.615 (gap of 0.09). L3, T1, T2 and 45-2 exhibit all values close to 0.5 for both components. And the relative gap between these two components is of the order to $10 \%$.

\begin{tabular}{|c|c|c|}
\hline Configuration & $\mathbf{A}_{\mathbf{x x}}$ & $\mathbf{A}_{\mathbf{y y}}$ \\
\hline L1 & 0.272 & 0.688 \\
\hline L3 & 0.549 & 0.416 \\
\hline T1 & 0.507 & 0.453 \\
\hline T2 & 0.466 & 0.496 \\
\hline $\mathbf{4 5 - 2}$ & 0.451 & 0.508 \\
\hline
\end{tabular}

Table 3. Experimental orientation tensor components for the five configurations with $y$ the injection direction. 


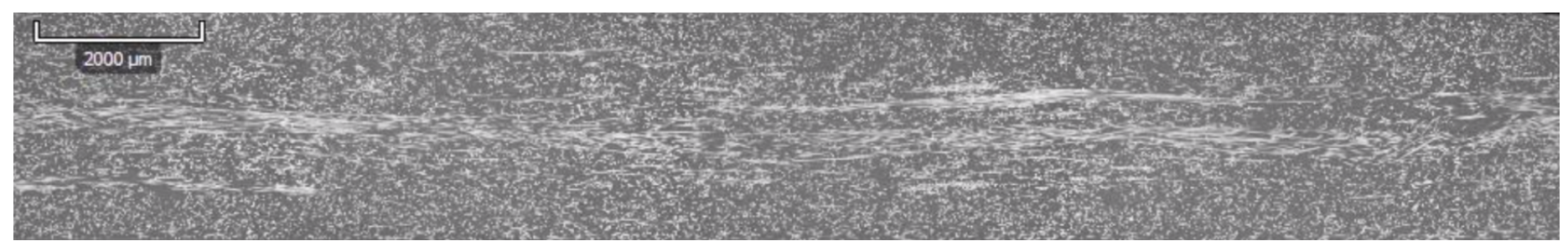

(a)

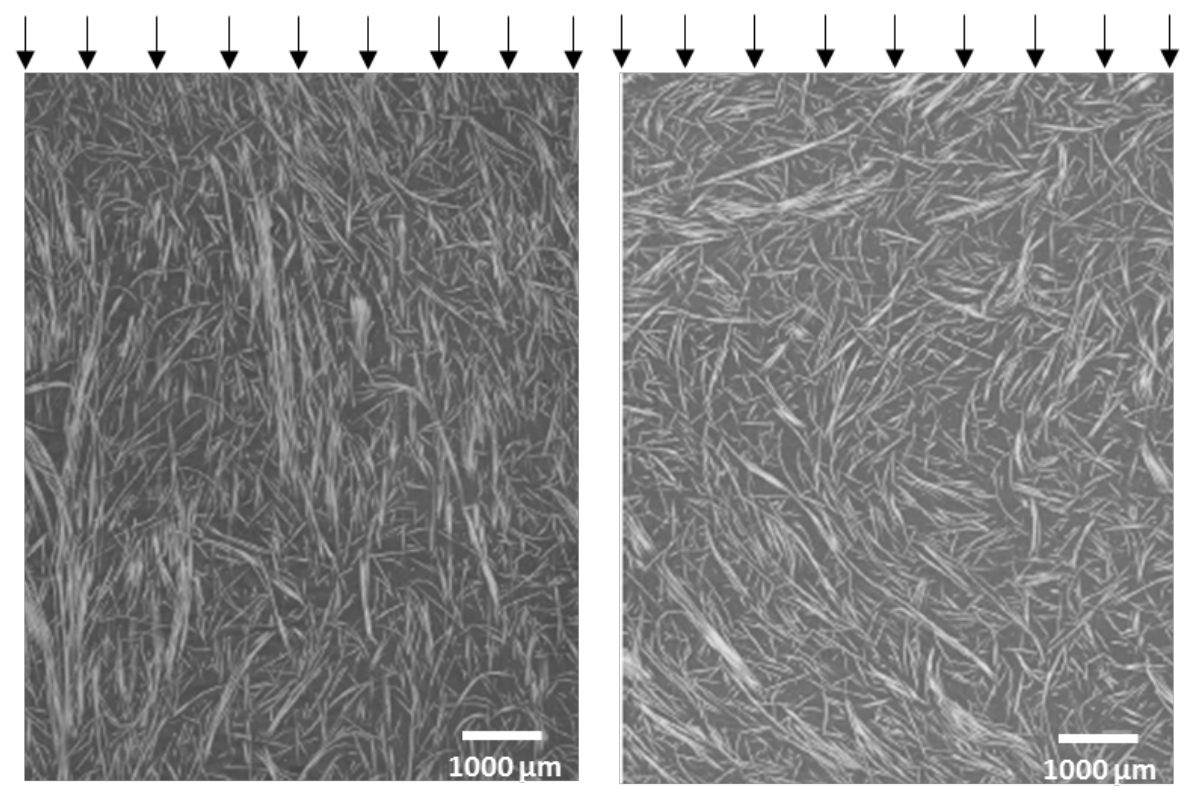

(b)

(c)

Fig. 3: X-ray micro-tomography images (a) skin-core structure in the thickness (b) on the outer surface for L1 and (b) L3. Fibers are white while the matrix is in grey and porosities are in black. The injection gate is located at the top of the plate and the black arrows are parallel to the injection direction.

\subsection{Mechanical behavior in tension}

Fig. 4 shows results of tensile tests performed up to rupture at room temperature for the different configurations. Samples are cut out from two different plates obtained with similar process conditions and respectively named $A$ and B. Testing results highlight a very good reproducibility for each orientation. A small dispersion is evidenced for each orientation and the relative gap on the stress level, calculated with respect to the minimum value, quantifies this dispersion. In the longitudinal direction, at $1.8 \%$ strain, a relative gap of $1 \%$ is calculated for $L 1$, whereas they are equal respectively to $4.8 \%$ and $7.7 \%$ for $L 2$ and $L 3$. Despite their close location to the injection gate, at a strain of $1 \%, \mathrm{~T} 1$ has a relative gap of $0.2 \%$, respectively $3.9 \%$ for $\mathrm{T} 2$. In addition, regarding $45-2$, a gap of $3 \%$ is calculated at a strain of $1.5 \%$. L1, T1 and 45-1 show the highest reproducibility whereas L3 shows the lowest one. L3, which seems to be the most random configuration in terms of fiber orientation, gives the highest dispersion in stress level. Though clusters are sometimes visible on X-ray micro-tomography images, the fiber volume fraction exhibits a weak dispersion on the plate; however, the fiber length exhibits a wide range of variation, with non-negligible fiber curvature. 


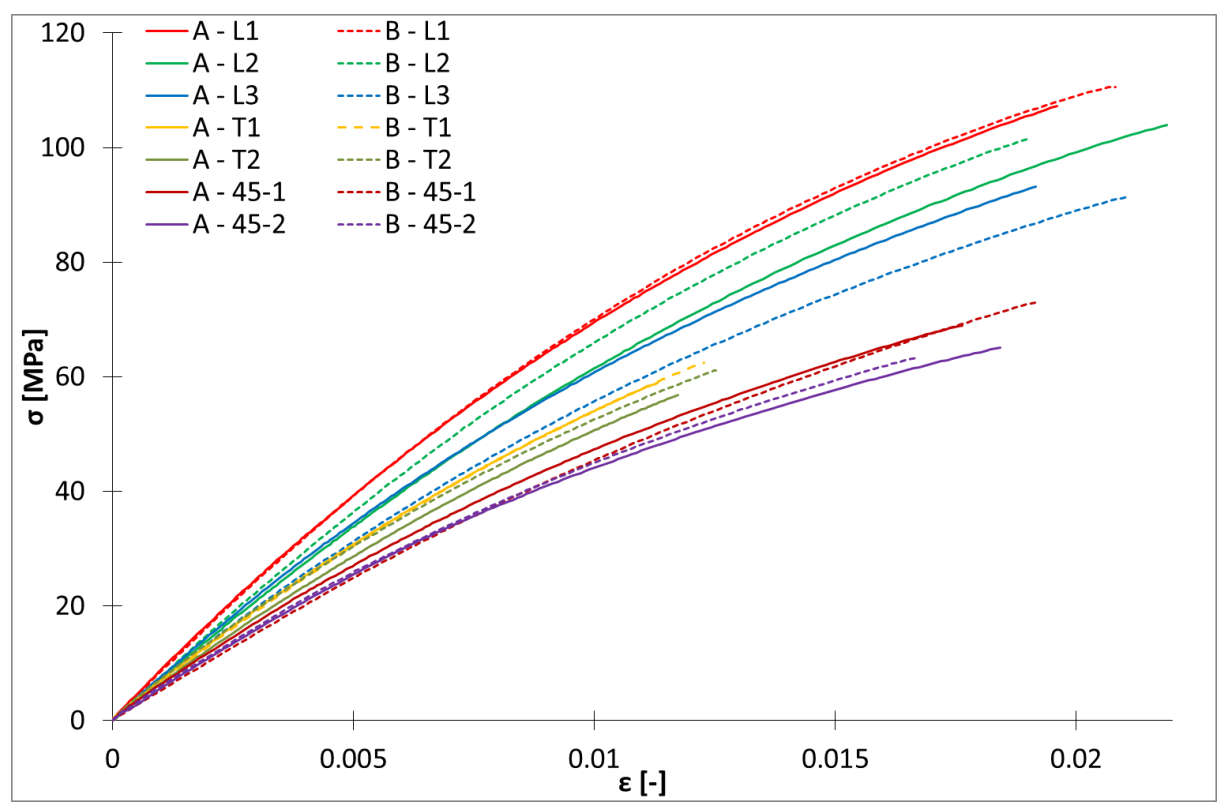

Fig. 4. Tensile test on PPGFL40 at $23^{\circ} \mathrm{C}$ and $10^{-4} \mathrm{~s}^{-1}$ for several configurations. A and B stand for two different plates.

The anisotropy of the mechanical behavior is rather strong, with a maximum stress level along the injection direction which can be divided by two for other configurations. L1 reaches the highest level of stress which is around $110 \mathrm{MPa}$. From L1 to L3, the stress level is reduced by $20 \mathrm{MPa}$. For each configuration, a strongly non-linear behavior is observed. It can also be seen that there is a clear distinction of the stress levels, without any overlapping of the curves. This validates the proposed cutting pattern and leads to a high reproducibility for each configuration, higher than results in literature $(21,22)$. Each configuration corresponds to a different average orientation tensor, with a particularly obvious difference for L1. Though the average orientation tensor is a local information, compared to the global information of the stress level, it seems that such a representation is relevant to distinguish the mechanical behavior.

Fig. 5 shows results of tensile tests performed for the same fiber orientations at $85^{\circ} \mathrm{C}$. For more visibility and to limit the number of tests, the analysis at elevated temperature is shown for only five orientations which are L1, L3, T1, T2 and 45-2. Only two representative curves for each configuration are presented. Same trends regarding the mechanical behavior observed at $23^{\circ} \mathrm{C}$ are noticed at $60^{\circ} \mathrm{C}$ and $85^{\circ} \mathrm{C}$. The weak dispersion of mechanical response is similar in temperature and is even enhanced for some orientations. Fig. 6 shows results of tensile tests for L1 and L3 at each temperature. It evidences the strong influence of the test temperature on the stress level. This effect does not depend on the fiber orientation. Indeed, similar decrease in term of stress level is observed with a maximum gap in between 20 and $30 \mathrm{MPa}$ at the same strain level. The general trend is observed for other configurations. 


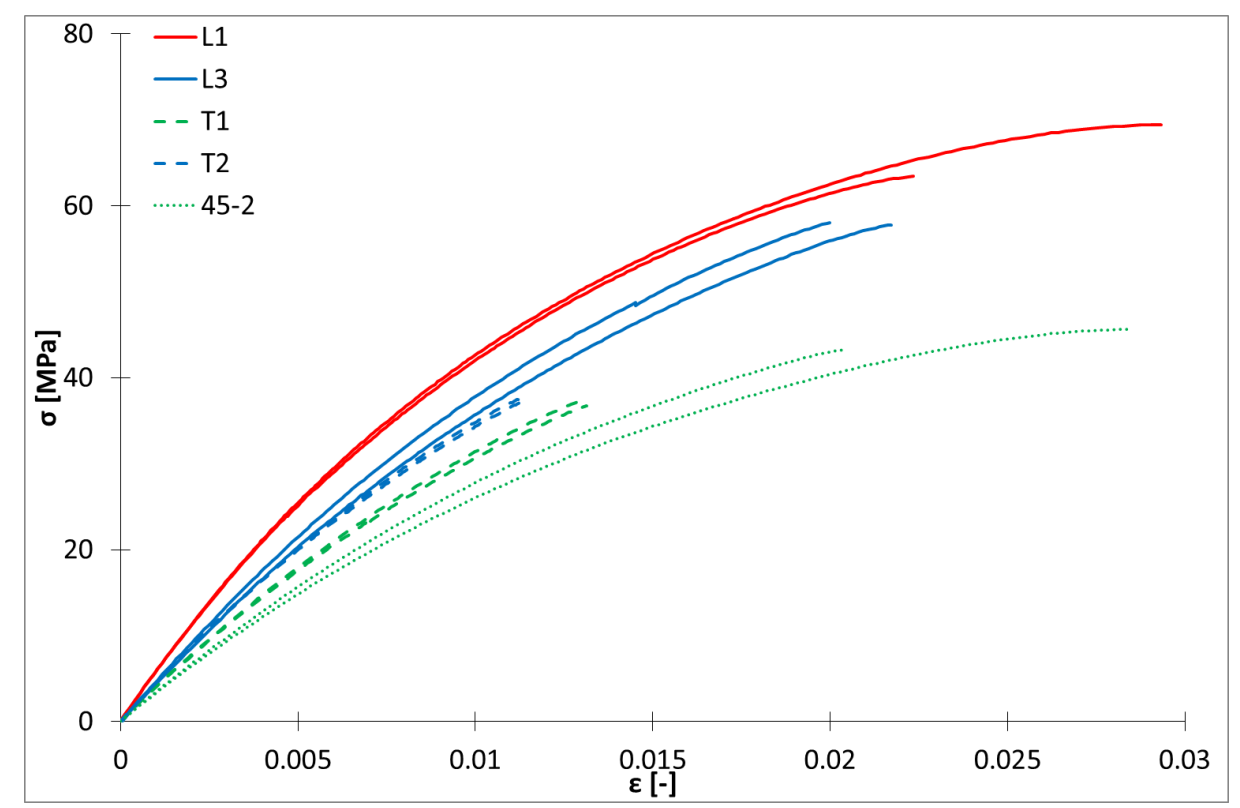

Fig. 5. Tensile test on PPGFL40 for all orientations at $85^{\circ} \mathrm{C}$, at $10^{-4} \mathrm{~s}^{-1}$ and for five configurations.

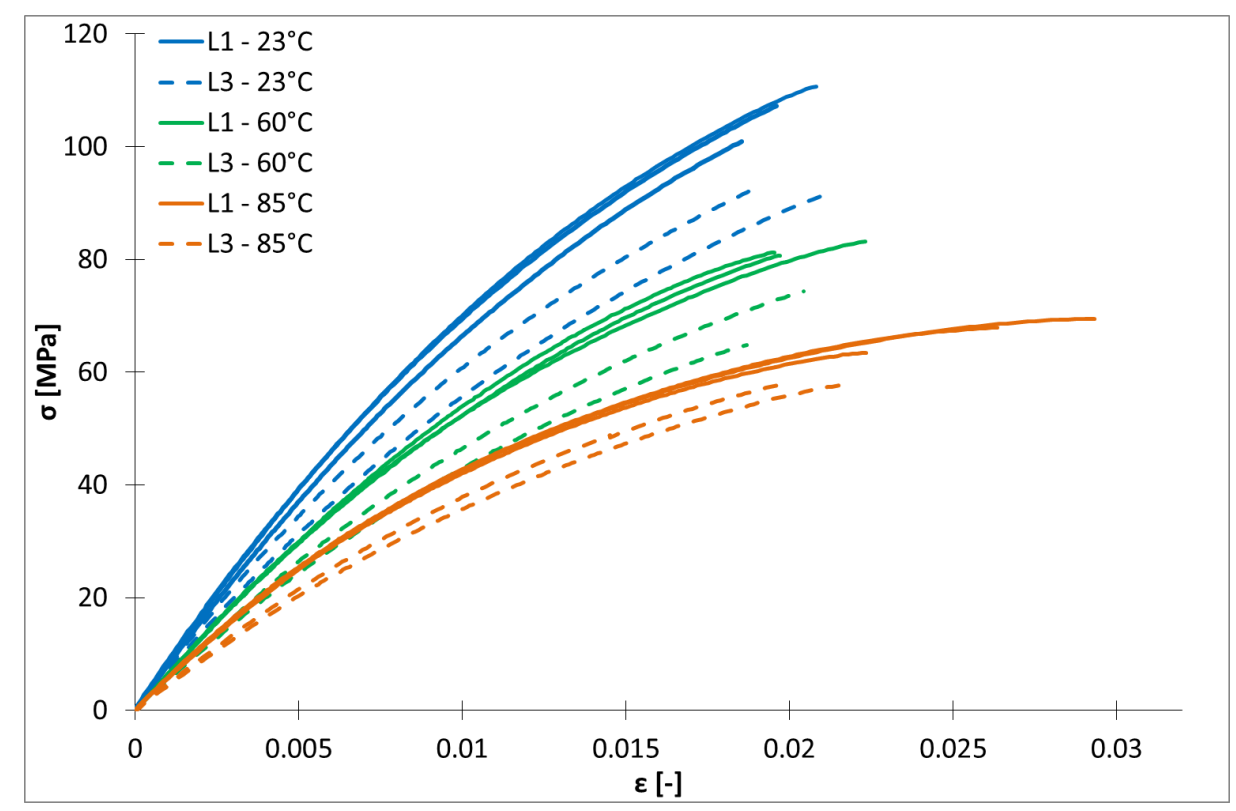

Fig. 6. Tensile test for $L 1$ and $L 3$ at different temperatures.

The influence of strain rate is investigated for three values, i.e. $10^{-5} \mathrm{~s}^{-1}, 10^{-4} \mathrm{~s}^{-1}$ and $10^{-3} \mathrm{~s}^{-1}$. Table 4 gives the initial slope of the stress-strain curve, referred as $E_{0}$, at three strain rates for L1 and L2. They are calculated on the corresponding stress/strain curves in the strain interval from $0.05 \%$ to $2.5 \%$ according to the standard NF EN ISO 527 1 and the value is averaged on several samples. It increases slightly when the strain rate increases. However, this effect is rather weak, with an average increase around 3\%, compared to the anisotropy effect.

\begin{tabular}{cccc}
\hline & $\mathbf{1 0 ^ { - 5 } \mathrm { s } ^ { - 1 }}$ & $\mathbf{1 0 ^ { - 4 } \mathrm { s } ^ { - 1 }}$ & $\mathbf{1 0 ^ { - 3 } \mathbf { s } ^ { - 1 }}$ \\
\hline $\mathbf{L 1}$ & 8127.54 & 8207.33 & 8460.94 \\
\hline $\mathbf{L 2}$ & 6889.35 & 7139.82 & 7547.73 \\
\hline
\end{tabular}

Table 4. $E_{0}(\mathrm{MPa})$ at $23^{\circ} \mathrm{C}$ obtained at several strain rates for $L 1$ and $L 2$. 
The evolution of $\mathrm{E}_{0}$ at three strain rates is also considered at $23^{\circ} \mathrm{C}$ and $85^{\circ} \mathrm{C}$ for $\mathrm{L} 1$, cf. Table 5 . The maximum relative gap is of $7.9 \%$ at $23^{\circ} \mathrm{C}$ and almost three times higher at $85^{\circ} \mathrm{C}$ which shows the viscoelastic effect. Nevertheless, some overlapping is observed at both temperatures. In the following section, only anisotropy and thermal dependence are considered.

\begin{tabular}{|c|c|c|c|c|}
\hline \multirow[b]{2}{*}{ Strain rate $\left(\mathrm{s}^{-1}\right)$} & \multicolumn{2}{|c|}{$23^{\circ} \mathrm{C}$} & \multicolumn{2}{|c|}{$85^{\circ} \mathrm{C}$} \\
\hline & $\mathrm{E}_{0}{ }^{\min }(\mathrm{MPa})$ & $\mathrm{E}_{0}{ }^{\max }(\mathrm{MPa})$ & $\mathrm{E}_{0}{ }^{\min }(\mathrm{MPa})$ & $\mathrm{E}_{0}{ }^{\max }(\mathrm{MPa})$ \\
\hline $10^{-5}$ & 8025.50 & 8229.58 & 4319.06 & 4783.75 \\
\hline $10^{-4}$ & 8185.54 & 8228.22 & 5154.26 & 5417.63 \\
\hline $10^{-3}$ & 8259.78 & 8662.10 & 5178.00 & 5460.50 \\
\hline
\end{tabular}

Table 5. Maximal and minimal values of $\mathrm{E}_{0}$ at $23^{\circ} \mathrm{C}$ and $85^{\circ} \mathrm{C}$ obtained at several strain rates for $\mathrm{L}$.

\section{Prediction of elastic properties}

The initial slope $E_{0}$ is derived from stress/strain curves and an average value is calculated on at least two samples for each orientation and each temperature. Fig. 7 shows experimental $E_{0}$ of PP and PPGFL40 obtained for several temperatures. At $23^{\circ} \mathrm{C}$ for PP, a value of $1000 \mathrm{MPa}$ is proposed by (27), similarly to (22). However, higher values of $1650 \mathrm{MPa}$ and $2000 \mathrm{MPa}$ are also obtained $(23,39)$, or also $566 \mathrm{MPa}$ at $85^{\circ} \mathrm{C}$ for $(40)$ which are closer to the average values respectively of $1700 \mathrm{MPa}$ and $587 \mathrm{MPa}$ measured in this study (cf. Table 1). Such a variation for PP modulus is therefore significant and is probably due to crystallinity rate resulting from different injection parameters. For each specimen, $E_{0}$ clearly decreases with the rising temperature. $E_{0}$ is predicted with equation 1 , proposed for PP and quasiunidirectional glass fiber/PP composites (27). Based on this equation, a compromise is found for all configurations, except T2, by reducing the value of $n$ from 2.3 for PP to 0.87 for the composite against 2.6. T2 is removed due to an inverse trend, i.e. $\mathrm{E}_{0}$ is close to $\mathrm{T} 1$ at a $23^{\circ} \mathrm{C}$ but much higher at $60^{\circ} \mathrm{C}$ and $85^{\circ} \mathrm{C}$.

$$
E(T)=E(R T) *\left(\frac{168-T}{168-23}\right)^{n}
$$

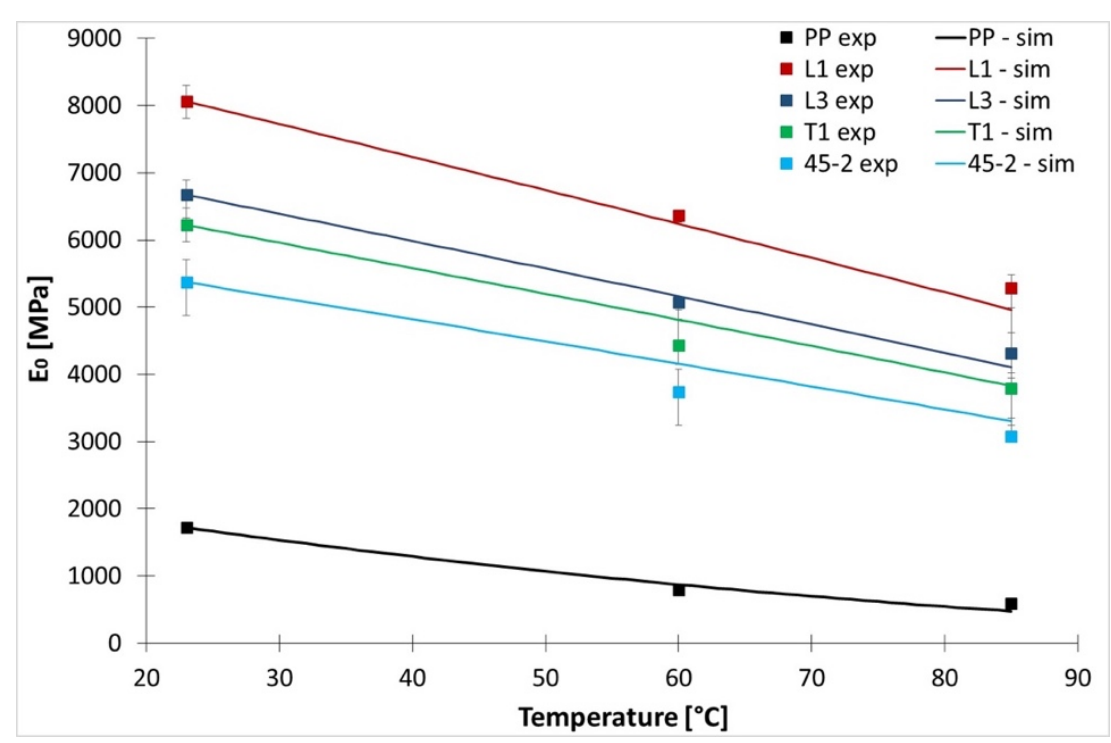

Fig. 7. Variation of $E_{0}$ for each fiber orientation at three temperatures and evolution predicted by the equation proposed in (27) for PP and PPGFL40. 
Evolution of $E_{0}$ for each configuration and temperature is also highlighted in Fig. 8. The highest dispersion is found at $23^{\circ} \mathrm{C}$ and mostly in the injection direction. Very close values of $\mathrm{E}_{0}$ for $45-2, \mathrm{~T} 1$ and $\mathrm{T} 2$ are found, which is consistent with results from literature (15). $E_{0}$ significantly reduces from in-flow direction to perpendicular-to-flow direction at all temperatures and strain rates. At $23^{\circ} \mathrm{C}$, the dispersion among all configurations is $33 \%$ regarding the highest value. For a similar material at $23^{\circ} \mathrm{C}$, a dispersion of $50 \%$ is obtained with specimen cut out from a $100 \times 20 \mathrm{~mm}^{2}$ plate and a gate in the middle of the longest edge (23). At $60^{\circ} \mathrm{C}$ and $85^{\circ} \mathrm{C}$, dispersion is about $42 \%$. The cutting pattern proposed in this study, based on fiber orientation, thus minimizes the dispersion. At $23^{\circ} \mathrm{C}, \mathrm{T} 1$ displays a higher $\mathrm{E}_{0}$ value than $\mathrm{T} 2$, but this trend is changed at elevated temperatures. Because $T 2$ is close to the injection gate, skin-core effect and dispersion could explain these results. Configuration 45-2 displays $E_{0}$ with the smallest value compared to other directions, whatever the temperature.

Moreover, from a technological point of view, these values obtained on samples cut out from a rectangular plate are compared to the ones measured on samples taken out of an industrial part (a front door made of the same material) in several areas and at different orientations to the injection direction. It is shown that they are representative of the industrial ones (41), thus highlighting the interest of the cutting pattern to evaluate a relevant range of mechanical properties.

Mori-Tanaka micromechanical model is then used to predict elastic properties, based on the average orientation tensor, fiber and matrix properties, fiber length ratio and temperature (42). This model is implemented in the software Digimat (43). Such a model has become very popular, as it leads to reasonable predictions in linear elasticity with fiber volume fractions up to $30 \%$ and out of simplicity's sake. The ability of such a micromechanical model to predict the elastic anisotropic properties of a $35 \mathrm{wt} \%$ short glass fiber reinforced polyamide 66 was already checked, based on numerical orientation tensors (20). Elastic properties in the configuration with fibers aligned to the injection direction are well described whereas some discrepancies are shown for other orientations.

In the present paper, the elastic tensor of the composite is calculated from i) the elastic tensors of the constituents, which is temperature-dependent for PP, ii) the fiber volume fraction and iii) the fiber shape factor. This factor, defined as the ratio of the fiber length over the fiber diameter, presents a large distribution coming from the relatively large variation of the fiber length. Therefore, three different values, i.e. 47, 36 and 25 are considered in this study. It should be stressed out that 47 is the value calculated from the median fiber length after the injection process. Fig. 8 presents a comparison between experimental values and numerical predictions for five configurations. It can be seen that the evolution of $E_{0}$ at ambient temperature is correctly predicted, though slightly overestimated for a shape factor equals to 47 , except for $\mathrm{L} 3$. The best compromise for the different configurations and temperatures is obtained for the shape factor of 47 , though the intermediate value of 36 also leads to close predictions for T1 and 45-2 configurations.

For the $L 3$ configuration, the orientation tensor component $A_{x x}$ is somehow surprisingly higher than $A_{y y}$, which can come from a limitation of the use of the average orientation tensor to fully represent the inhomogeneity of microstructure. For T1, T2 and 45-2, the two component values are close. Nevertheless, the evolution of $\mathrm{E}_{0}$ seems related not only to the component value but also to the gap between $A_{x x}$ and $A_{y y}$, this one being maximum for the strongly-orientated configuration L1 and of the order of $10 \%$ of the maximum component for T1, T2 and $45-2$. 
Mechanical properties of configuration L3 are clearly underestimated. A further trend should be to consider the full heterogeneity of the microstructure, without any average over the thickness.

Concerning the thermal dependence, the decrease of $E_{0}$ comes only from the PP properties. Except for $L 3$ and T2 configurations, the slight overestimation of the predictions at $23^{\circ} \mathrm{C}$ and $60^{\circ} \mathrm{C}$ increases significantly at $85^{\circ} \mathrm{C}$. It could come from an overestimation of the Young's modulus of PP at this temperature; indeed, the presence of fibers and the injection conditions of the composite may affect the properties of the material, different when tested by itself or a composite.

It can be concluded that such an approach gives a realistic prediction of the anisotropic thermo-dependent elastic properties of the material, though some configurations necessitate taking account of the full heterogeneity, i.e. in the thickness, of the material.

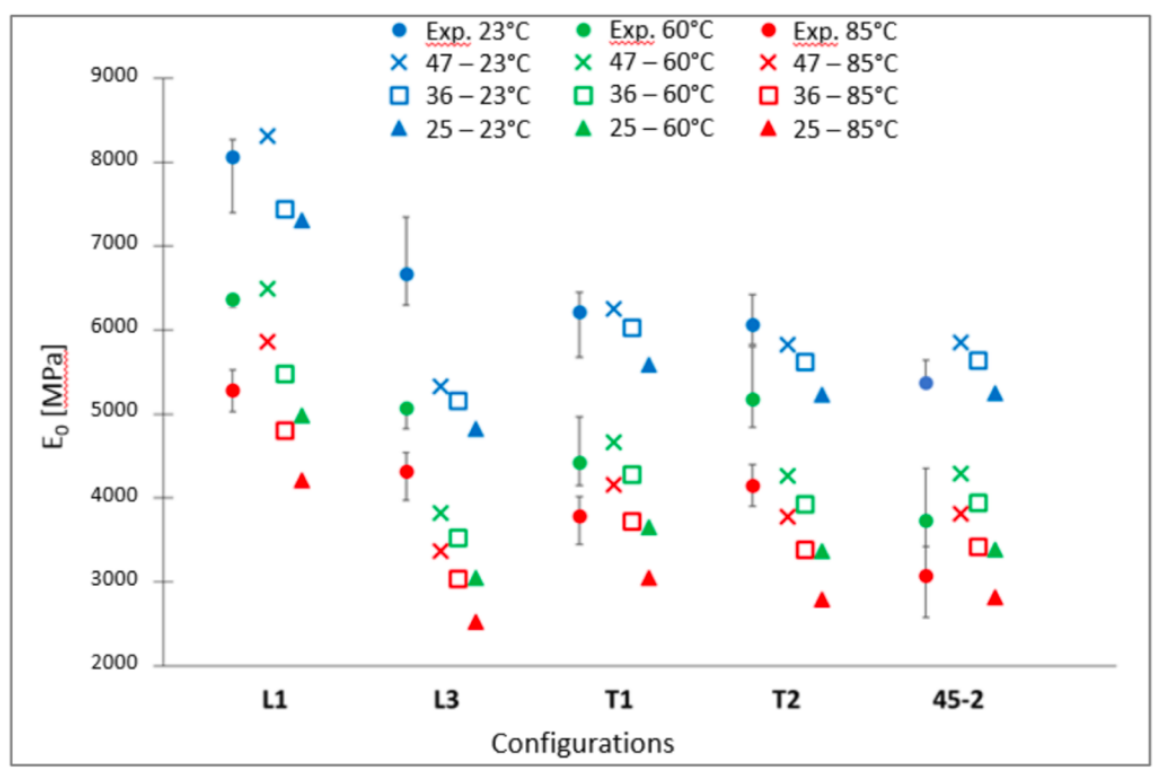

Fig. 8. Experimental dispersion (full circle) on $E_{0}$ for each configuration at three temperatures and a strain rate of $10^{-4} \mathrm{~s}^{-1}$. The three colors correspond to different temperatures. The measured variation is also highlighted with error bars. Predicted values with Mori-Tanaka's model, using three different shape factors, are also plotted. The cross, square and full triangle respectively corresponds to shape factor values of 47,36 and 25 .

\section{Conclusions}

This study is dedicated to the thermo-mechanical characterization of a discontinuous glass fiber reinforced PP with a mass fraction of $40 \%$, with a focus on the prediction of the anisotropic thermo-dependent elastic properties. Rectangular plates are injected using the same conditions as industrial parts. Samples are cut out following an original pattern that leads to a large range of stress levels and elastic properties, comparable to those recorded out of an industrial part. Tensile tests are performed at three different temperatures. It is shown that the dispersion on the mechanical properties is rather low compared to other patterns proposed in the literature. The initial slope of the stress-strain curve decreases with temperature by a factor of 1.5 between $23^{\circ} \mathrm{C}$ and $85^{\circ} \mathrm{C}$. Predictions of the elastic properties with Mori-Tanaka micromechanical model are compared with experimental values, for different temperatures and configurations. The overall trend at ambient temperature is correctly described; however, the elastic properties of the configuration presenting a highly heterogeneous microstructure are underestimated. 


\section{Acknowledgements}

The authors wish to acknowledge support from RENAULT SAS and the French agency ANRT for the grant $n^{\circ} 2014 / 0614$.

Declaration of Conflicting Interests: The Authors declares that there is no conflict of interest

\section{$\underline{\text { References }}$}

1. Klimkeit B, Nadot $\mathrm{Y}$, Castagnet S, Nadot-Martin C, Dumas C, Bergamo S, et al. Multiaxial fatigue life assessment for reinforced polymers. Int J Fatigue. 2011;33(6):766-80.

2. Bernasconi A, Davoli P, Armanni C. Fatigue strength of a clutch pedal made of reprocessed short glass fibre reinforced polyamide. Int J Fatigue. 2010;32(1):100-7.

3. Sonsino CM, Moosbrugger E. Fatigue design of highly loaded short-glass-fibre reinforced polyamide parts in engine compartments. Int J Fatigue. 2008;30(7):1279-88.

4. Sun X, Lasecki J, Zeng D, Gan Y, Su X, Tao J. Measurement and quantitative analysis of fiber orientation distribution in long fiber reinforced part by injection molding. Polym Test.

2015;42:168-74.

5. Schijve W. Common errors and honest materials comparison for long glass PP materials. In: International AVK conference for reinforced plastics and thermoset molding compounds. BadenBaden; 2002. p. 17-8.

6. Lopez-Manchado MA, Arroyo M. Thermal and dynamic mechanical properties of polypropylene and short organic fiber composites. Polymer. 2000;41(21):7761-7767.

7. Ashori A, Menbari S, Bahrami R. Mechanical and thermo-mechanical properties of short carbon fiber reinforced polypropylene composites using exfoliated graphene nanoplatelets coating. J Ind Eng Chem. 2016;38:37-42.

8. Do V-T, Nguyen-Tran H-D, Chun D-M. Effect of polypropylene on the mechanical properties and water absorption of carbon-fiber-reinforced-polyamide-6/polypropylene composite. Compos Struct. 2016;150:240-5.

9. Lopez D, Thuillier S, Grohens Y, Bessières N. Anisotropic Mechanical Behavior of an Injection Molded Short Fiber Reinforced Thermoplastic. In: AIP Conference Proceedings. Nantes: AIP Publishing; 2016. p. 060007.

10. Dray Bensahkoun D. Prediction of the thermoelastic properties of an injection molded short-fiber composite - Thesis [Thèse en doctorat]. Arts et Métiers ParisTech; 2006.

11. Bernasconi A, Davoli P, Basile A, Filippi A. Effect of fibre orientation on the fatigue behaviour of a short glass fibre reinforced polyamide-6. Int J Fatigue. 2007;29(2):199-208.

12. Redjeb A, Silva $L$, Laure $P$, Vincent $M$, Coupez $T$. Three dimensional numerical simulations of fiber orientation in injection molding. In 2002. p. 366-71.

13. Nguyen HG. Approche micromécanique pour la modélisation du comportement élasto-plastique des composites : application aux mortiers de résine [Thèse en doctorat]. 2008. 
14. Notta-Cuvier D, Lauro F, Bennani B, Balieu R. Damage of short-fibre reinforced materials with anisotropy induced by complex fibres orientations. Mech Mater. 2014;68:193-206.

15. Mortazavian S, Fatemi A. Effects of fiber orientation and anisotropy on tensile strength and elastic modulus of short fiber reinforced polymer composites. Compos Part B Eng. 2015a;72:116-29.

16. Launay A, Marco Y, Maitournam MH, Raoult I, Szmytka F. Cyclic behavior of short glass fiber reinforced polyamide for fatigue life prediction of automotive components. Procedia Eng Conf Proc. 2010;2(1):901-10.

17. Gehring F, Bouchart V, Dinzart F, Chevrier P. Etude expérimentale et modélisation du comportement de polymères thermoplastiques renforcés: polypropylène chargé de fibres de chanvre. In: 20ème Congrès Français de Mécanique -25044. Besançon; 2011.

18. Arao Y, Yumitori S, Suzuki H, Tanaka T, Tanaka K, Katayama T. Mechanical properties of injectionmolded carbon fiber/polypropylene composites hybridized with nanofillers. Compos Part Appl Sci Manuf. 2013;55:19-26.

19. De Monte M, Moosbrugger E, Quaresimin M. Influence of temperature and thickness on the off-axis behaviour of short glass fibre reinforced polyamide 6.6 - cyclic loading. Compos Part Appl Sci Manuf. 2010;41:1368-79.

20. Launay A, Maitournam MH, Marco Y, Raoult I. Multiaxial fatigue models for short glass fiber reinforced polyamide - Part I: Nonlinear anisotropic constitutive behavior for cyclic response. Int J Fatigue. 2013;47:382-9.

21. Jain A, Paepegem WV, Verpoest I, Lomov SV. A statistical treatment of the loss of stiffness during cyclic loading for short fiber reinforced injection molded composites. Compos Part B Eng. 2016;103:40-50.

22. Notta-Cuvier D, Nciri M, Lauro F, Delille R, Chaari F, Robache F, et al. Coupled influence of strain rate and heterogeneous fibre orientation on the mechanical behaviour of short-glass-fibre reinforced polypropylene. Mech Mater. 2016;100:186-97.

23. Barbosa SE, Kenny JM. Analysis of the relationship between processing conditions - fiber orientation final properties in short fiber reinforced polypropylene. J Reinf Plast Compos. 1999;18:0731-6844.

24. Mouhmid B, Imad A, Benseddiq N, Benmedakhène $S$, Maazouz A. A study of the mechanical behaviour of a glass fibre reinforced polyamide 6,6: Experimental investigation. Polym Test. juin 2006;25(4):544-52.

25. Mortazavian S, Fatemi A. Fatigue behavior and modeling of short fiber reinforced polymer composites including anisotropy and temperature effects. Int J Fatigue. 2015b;77:12-27.

26. Şerban DA, Weber G, Marşavina L, Silberschmidt VV, Hufenbach W. Tensile properties of semicrystalline thermoplastic polymers: Effects of temperature and strain rates. Polym Test. 2013;32(2):413-25.

27. Zhai Z, Gröschel C, Drummer D. Tensile behavior of quasi-unidirectional glass fiber/polypropylene composites at room and elevated temperatures. Polym Test. 2016;54:126-33.

28. Teixeira D, Giovanela M, Gonella LB, Crespo JS. Influence of injection molding on the flexural strength and surface quality of long glass fiber-reinforced polyamide 6.6 composites. Mater Des. 
29. Coulon A, Lafranche E, Douchain C, Krawczak P, Ciolczyk JP, Gamache E. Flexural creep behaviour of long glass fibre reinforced polyamide 6.6 under thermal-oxidative environment. J Compos Mater. 2016;0:0-14.

30. Lafranche E, Coulon A, Krawczak P, Ciolczyk JP, Gamache E. A microstructural approach for modelling flexural properties of long glass fibre reinforced polyamide 6.6. J Compos Mater. 2016;51(1):3-16.

31. Rezaei F, Yunus R, Ibrahim NA. Effect of fiber length on thermomechanical properties of short carbon fiber reinforced polypropylene composites. Mater Des. févr 2009;30(2):260-3.

32. Terahertz Waves Technologies [Internet]. http://www.t-waves-technologies.com/. 2017. Disponible sur: http://www.t-waves-technologies.com/

33. Albrecht K, Baur E, Endres H-J, Gente R, Graupner N, Koch M, et al. Measuring fibre orientation in sisal fibre-reinforced, injection moulded polypropylene - Pros and cons of the experimental methods to validate injection moulding simulation. Compos Part Appl Sci Manuf. 2017;95:54-64.

34. Dean A, Reinoso J, Sahraee S, Rolfes R. An invariant-based anisotropic material model for short fiberreinforced thermoplastics: Coupled thermo-plastic formulation. Compos Part Appl Sci Manuf. 2016;90:186-99.

35. Novitom. http://www.novitom.com/en/. 2017.

36. Advani SG, Tucker III CL. The use of tensors to describe and predict fiber orientation in short fiber composites. J Rheol. 1987;31(8):751-84.

37. Andriyana A, Billon N, Silva L. Mechanical response of a short fiber-reinforced thermoplastic: Experimental investigation and continuum mechanical modeling. Eur J Mech - ASolids. 2010;29(6):1065-77.

38. Ogierman W, Kokot $\mathrm{G}$. A study on fiber orientation influence on the mechanical response of a short fiber composite structure. Acta Mech. janv 2016;227(1):173-83.

39. Parenteau T, Bertevas E, Ausias G, Stocek R, Grohens Y, Pilvin P. Characterisation and micromechanical modelling of the elasto-viscoplastic behavior of thermoplastic elastomers. Mech Mater. avr 2014;71:114-25.

40. Eftekhari M, Fatemi A. Creep behavior and modeling of neat, talc-filled, and short glass fiber reinforced thermoplastics. Compos Part B Eng. 2016;97:68-83.

41. Lopez D. Comportement d'un thermoplastique renforcé de fibres de verre soumis à des chargements thermomécaniques. Université Bretagne Sud; 2018 (in French).

42. Mori T, Tanaka K. Average stress in matrix and average elastic energy of materials with misfitting inclusions. Acta Metall. 1973;21(5):571-4.

43. Digimat 2018 version 4.1.2. Linear and nonlinear multi-scale material software, e-Xtream engeneering, MSC softwate compagny. http://www.e-xstream.com/. 